\title{
Structural Changes of Lignin after Liquid Hot Water Pretreatment and Its Effect on the Enzymatic Hydrolysis
}

\author{
Wen Wang, ${ }^{1}$ Xinshu Zhuang, ${ }^{1}$ Zhenhong Yuan, ${ }^{1,2}$ Wei Qi, ${ }^{1}$ Qiang Yu, ${ }^{1}$ and Qiong Wang \\ ${ }^{1}$ Key Laboratory of Renewable Energy and Guangdong Key Laboratory of New and Renewable Energy Research and Development, \\ Guangzhou Institute of Energy Conversion, Chinese Academy of Sciences, Guangzhou 510640, China \\ ${ }^{2}$ Collaborative Innovation Center of Biomass Energy, Zhengzhou 450002, China
}

Correspondence should be addressed to Zhenhong Yuan; yuanzh@ms.giec.ac.cn

Received 14 March 2016; Accepted 13 June 2016

Academic Editor: Encarnación Ruiz

Copyright (C) 2016 Wen Wang et al. This is an open access article distributed under the Creative Commons Attribution License, which permits unrestricted use, distribution, and reproduction in any medium, provided the original work is properly cited.

\begin{abstract}
During liquid hot water (LHW) pretreatment, lignin is mostly retained in the pretreated biomass, and the changes in the chemical and structural characteristics of lignin should probably refer to re-/depolymerization, solubilization, or glass transition. The residual lignin could influence the effective enzymatic hydrolysis of cellulose. The pure lignin was used to evaluate the effect of LHW process on its structural and chemical features. The surface morphology of LHW-treated lignin observed with the scanning electron microscopy (SEM) was more porous and irregular than that of untreated lignin. Compared to the untreated lignin, the surface area, total pore volume, and average pore size of LHW-treated lignin tested with the Brunner-Emmet-Teller (BET) measurement were increased. FTIR analysis showed that the chemical structure of lignin was broken down in the LHW process. Additionally, the impact of untreated and treated lignin on the enzymatic hydrolysis of cellulose was also explored. The LHW-treated lignin had little impact on the cellulase adsorption and enzyme activities and somehow could improve the enzymatic hydrolysis of cellulose.
\end{abstract}

\section{Introduction}

Bioethanol production from lignocellulosic biomass has gained focus for easy availability of feedstock, no competition with the food supply, and reduction in net carbon emission $[1,2]$. Cellulose, hemicellulose, and lignin which are the main components of lignocellulosic materials form complex and compact structure via covalent and noncovalent bonds to make lignocellulose resist the microbial and enzymatic attack [1]. Pretreatment followed by enzymatic hydrolysis and fermentation is an essential process for the effective bioconversion of lignocellulose to ethanol. The pretreatment can lead to changes in the structure and chemical composition of biomass and thus create new features for the pretreated biomass [3]. Liquid hot water (LHW) which is a hydrothermal pretreatment makes the pretreated biomass mainly composed of cellulose and lignin [4]. The residual lignin in the pretreated lignocellulose can negatively influence the enzymatic hydrolysis of cellulose via physical barrier and enzyme adsorption [4-6], and its chemical and structural characteristics are changed due to depolymerization and condensation reactions during LHW pretreatment [7]. Ko et al. [7] extracted lignin from LHW-pretreated hardwoods at four different severities through extensive enzymatic hydrolysis and found that lignin that suffered at more severity of LHW pretreatment exhibited more significant inhibition on enzymatic hydrolysis. The pretreatment type, biomass source, and isolation method determined the characteristics of lignin which would exhibit various impacts on enzymatic hydrolysis [8].

The authors found that a part of cellulose always existed in lignin extractive through the extensive enzymatic hydrolysis of LHW-treated lignocellulose. The residual cellulose in lignin extractive may influence the following research such as enzyme adsorption and enzymatic hydrolysis. In general, the milled wood lignin (MWL) and cellulolytic enzyme lignin (CEL) have been thought to nearly resemble the native lignin. However, the ball-milling process for isolating MWL could result in $\beta$-ether cleavage [9], and the isolation procedure for CEL could increase phenolic $\beta$-O-4 content [10] and 
reduce molecular weight [11]. Recently, She et al. [12] reported that alkali could not change the main structural feature of lignin preparations isolated with $50 \%$ dioxane. Although the MWL and CEL have been used as representative sources for structural and chemical analysis of lignin, the application of alkali lignin for further analysis might provide compensatory research. Alkali lignin has seldom been used for characteristic analysis of lignin mainly due to its high amount of nonlignin components, especially hemicellulose [13]. In this study, the relative pure alkali lignin was used to investigate the effect of LHW pretreatment on structural and chemical changes of lignin. The effect of LHW-treated lignin on enzymatic hydrolysis of pure cellulose was investigated. This study was a preliminary try to explore the structural and chemical changes of lignin in the LHW process and would provide useful information for the future research.

\section{Materials and Methods}

2.1. Materials. The alkali lignin with $5 \%$ moisture (Product ID: 370595) was purchased from Sigma-Aldrich (Shanghai) Trading Co., Ltd. It was composed of $85.0 \%$ lignin, $1.3 \%$ glucan, and $1.3 \%$ xylan. Whatman number 1 filter papers were purchased from Guangzhou Maolin Instrument Co., Ltd. (China). Cellulase whose filter paper activity was $151.7 \mathrm{FPU} / \mathrm{g}$ powder was purchased from Imperial Jade Bio-technology Co. Ltd. (China).

2.2. Pretreatment. The alkali lignin was pretreated by liquid hot water under the condition of $180^{\circ} \mathrm{C}, 4 \mathrm{MPa}, 20 \mathrm{~min}$, which was the optimized operation in the previous study [14]. The ratio of lignin to water was $1: 20(\mathrm{~g}: \mathrm{mL})$. After pretreatment, the solid residue was air-dried at room temperature and then stored in the desiccator. The LHW-treated lignin was composed of $90.7 \%$ lignin and $1.4 \%$ glucan.

Whatman number 1 filter papers were cut into pieces in size of less than $1 \mathrm{~cm} \times 1 \mathrm{~cm}$. The pieces were ground at $25000 \mathrm{rpm}$ for $1 \mathrm{~min}$ with the swing pulverizer (Guangzhou Daxiang Electronic Machinery Co., Ltd., China) and then stored in the desiccator.

2.3. Enzymatic Hydrolysis. The filter paper and lignin mixed in the mass ratio of $0.1: 0.03$ were loaded into a $5 \mathrm{~mL}$ Eppendorf tube containing $2.6 \mathrm{~mL} 0.05 \mathrm{M}$ citrate buffer $(\mathrm{pH}$ 4.8). The tubes were sealed with parafilm and fixed on a salver and then placed into a rotatory shaker which was set at $50^{\circ} \mathrm{C}, 150 \mathrm{rpm}$. The hydrolysis was performed for $72 \mathrm{~h}$ with the cellulase loadings of $5,10,20$, and $40 \mathrm{FPU} / \mathrm{g}$ filter paper. The filter papers hydrolyzed under the same conditions without lignin addition were used as the controls. Meanwhile, the filter paper mixing with lignin in the mass ratio of 0.1:0.05 was also hydrolyzed with $15 \mathrm{FPU} / \mathrm{g}$ filter paper cellulase loadings under the same condition.

2.4. Enzyme Activity Assay. The enzyme solution was prepared with $0.198 \mathrm{~g}$ cellulase and $10 \mathrm{~mL} 0.05 \mathrm{M}$ citrate buffer ( $\mathrm{pH}$ 4.8). The Eppendorf tubes containing $3 \mathrm{~mL}$ enzyme solution with and without $30 \mathrm{mg}$ lignin were sealed with parafilm and taped on a salver and then placed into a rotatory shaker at the speed of $150 \mathrm{rpm}$. After incubating at $50^{\circ} \mathrm{C}$ for $60 \mathrm{~min}$, the filter paper and CMCase activities of the samples were assayed according to the described methods [15]. The $\beta$-glucosidase activity was assayed with p-nitrophenyl- $\beta$-Dglucopyranoside (pNPG) method described in [16].

2.5. Adsorption. The filter paper, lignin, and their mixture in the mass ratio of $0.6: 0.3$ were loaded into $50 \mathrm{~mL}$ conical flasks containing $20 \mathrm{~mL}$ enzyme solution, respectively. The cellulase loading was $20 \mathrm{FPU} / \mathrm{g}$ filter paper. The flasks were placed into a rotatory shaker under the condition of $50^{\circ} \mathrm{C}$, $150 \mathrm{rpm}$. The solutions with volume of $200 \mu \mathrm{L}$ were taken at 5 , $10,15,20,40,60,80,100,120$, and $180 \mathrm{~min}$. The protein content was quantified according to the previous method [4]. All of the experiments in this study were in duplicate.

2.6. Analytic Methods. Compositional analysis was carried out as the procedure described by the National Renewable Energy Laboratory (NREL) [17]. Lignin treated with and without LHW was coated with a thin layer of gold and then observed with a scanning electron microscope (SEM, S-4800, Hitachi) under an accelerating voltage of $2.0 \mathrm{kV}$. FTIR test was conducted according to the described $\mathrm{KBr}$ pellet technique with a TENSOR 27 Fourier transform infrared spectrometer (Bruker Optics, Germany) [18]. The special surface area, pore size, and total pore volume of lignin were analyzed with the automated surface and porosity analyzer (SI-MP10/PoreMaster 33, Quantachrome Instruments, USA). Sulfur content of lignin was determined with the elemental analyzer (vario EL cube, Germany). The HPLC system (Waters 2698, USA) equipped with a sugar column (SH1011, Shodex) was applied to measure the sugar concentrations at $50^{\circ} \mathrm{C}$ with $5 \mathrm{mM} \mathrm{H}_{2} \mathrm{SO}_{4}$ used as the mobile phase at the flow rate of $0.5 \mathrm{~mL} / \mathrm{min}$.

\section{Results and Discussion}

3.1. Surface Structure. Liquid hot water is a promising green pretreatment. LHW-treated biomass is mainly composed of cellulose and lignin. LHW pretreatment caused the redistribution of lignin which could influence the enzymatic hydrolysis [19]. In order to discover the changes of lignin during LHW pretreatment, pure alkali lignin was used in this study to avoid the interruption from cellulose and hemicellulose. The pure lignin which was pretreated at $180^{\circ} \mathrm{C}, 4 \mathrm{MPa}$, for 20 min was air-dried at room temperature to alleviate the influence of high oven temperature on the surface structure [20]. The photographs and SEM observed morphologies of untreated and treated lignin were shown in Figure 1. The untreated lignin was brown and granular (Figure 1(a)), while the treated lignin was yellow and powdered (Figure 1(b)). As for the SEM observed morphologies, the untreated lignin was smooth (Figure 1(c)), while the treated lignin was porous and irregular (Figure 1(d)). These indicated that changes happened to lignin during LHW pretreatment. It was reported that lignin can be melted at temperatures from $170^{\circ} \mathrm{C}$ to $180^{\circ} \mathrm{C}$ and redeposited with the temperature decreasing [21]. 


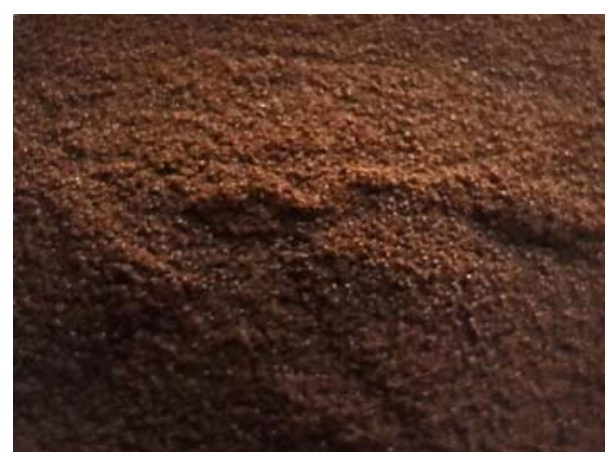

(a)

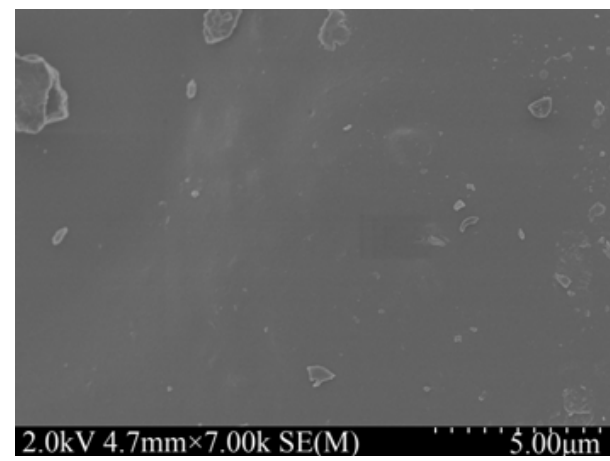

(c)

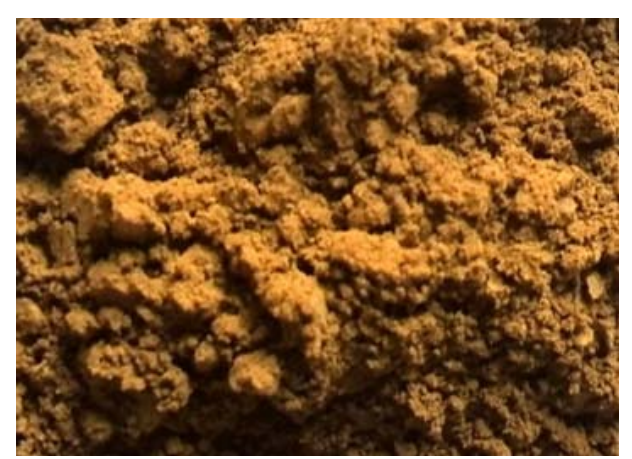

(b)

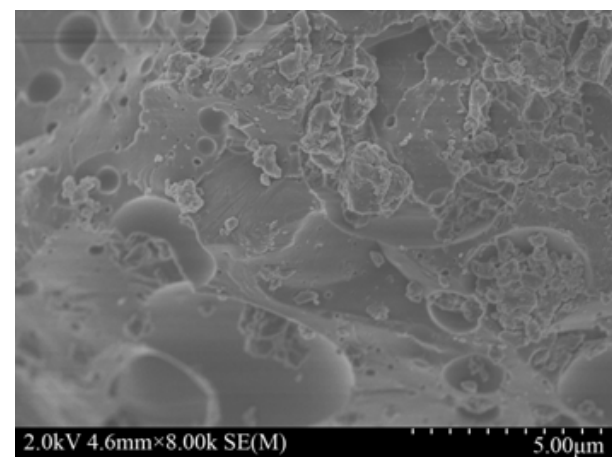

(d)

FIGURE 1: Photographs and SEM observed morphologies of LHW-untreated and LHW-treated lignin, (a) photograph of untreated lignin, (b) photograph of treated lignin, (c) SEM observed untreated lignin, and (d) SEM observed treated lignin.

The surface changes of lignin were quantified with the BET analysis. The BET results of untreated and treated lignin were shown in Table 1. Compared with the untreated lignin, the surface area, total pore volume, and average pore size of treated lignin were raised nearly four times, eight times, and one time, respectively. The increase of surface area meant that the adsorption of cellulase to lignin might be improved. The increase in total pore volume and average pore size might contribute to the access of cellulase to cellulose. It might be deduced that there might be double effects of LHWtreated lignin on the enzymatic hydrolysis. One was that the lignin reduced the cellulolytic efficiency through adsorbing cellulase; the other was that the increase in the pore size of lignin could improve the access of cellulase to cellulose.

3.2. FTIR Analysis. The changes of the chemical groups were analyzed with FTIR method. The result was presented in Figure 2. The spectrogram shape of the untreated and treated lignin was almost the same, but the absorbance of treated lignin was stronger than that of untreated lignin, which meant that either new chemical groups were formed or new connections of chemical bonds were built in the LHW process. The band at $3600-3050 \mathrm{~cm}^{-1}$ is assigned to $\mathrm{O}-\mathrm{H}$ stretching vibration which is attributed to the aliphatic and phenolic hydroxyl groups in lignin [22]. The intermolecular and intramolecular hydrogen bonds existed in the aliphatic and phenolic hydroxyl groups, such

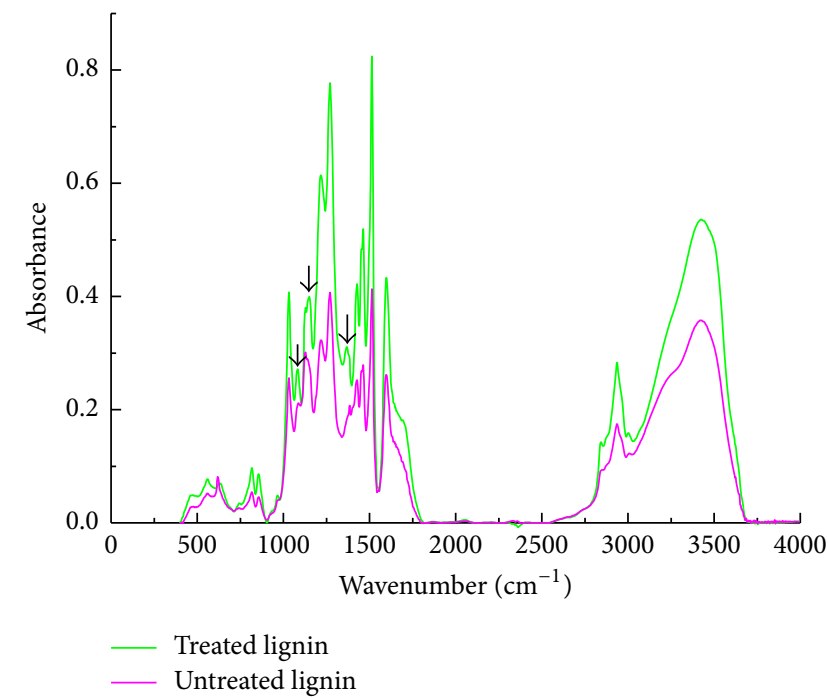

FIGURE 2: FTIR spectrograms of LHW-untreated and LHW-treated lignin.

as $\mathrm{O}(2) \mathrm{H} \cdots \mathrm{O}(6)$ intramolecular $\mathrm{H}$-bond, $\mathrm{O}(3) \mathrm{H} \cdots \mathrm{O}(5)$ intramolecular $\mathrm{H}$-bond, and $\mathrm{O}(6) \mathrm{H} \cdots \mathrm{O}\left(3^{\prime}\right)$ intermolecular $\mathrm{H}$-bond. The stronger absorbance of LHW-treated lignin indicated that, after LHW pretreatment, the H-bond connections of the aliphatic and phenolic hydroxyl groups might be improved or new free hydroxyl groups might be formed in the 
TABLE 1: BET measurements of the LHW-untreated and LHW-treated lignin.

\begin{tabular}{lccr}
\hline & Surface area $\left(\mathrm{m}^{2} / \mathrm{g}\right)$ & Total pore volume $(\mathrm{cc} / \mathrm{g})$ & Average pore diameter $(\mathrm{nm})$ \\
\hline Untreated lignin & 27.12 & 0.06 & 8.78 \\
Treated lignin & 125.81 & 0.53 & 16.87 \\
\hline
\end{tabular}

TABLE 2: Assignments of characteristic peaks in FTIR spectrogram.

\begin{tabular}{ll}
\hline Wavenumber $\left(\mathrm{cm}^{-1}\right)$ & Assignments of characteristic peaks \\
\hline 2937 & C-H stretching vibrations in methyl and methylene \\
1597 & Stretching vibrations of aromatic skeleton and C=O \\
1514 & Vibrations of aromatic skeleton \\
1463 & C-H deformations in methyl \\
1427 & Plane deformation of C-H in aromatic skeleton \\
1271 & Stretching vibrations of guaiacyl ring and C=O \\
1217 & Stretching vibrations of C-C, C-O, and C=O \\
1032 & Plane deformations of aromatic C-H, C-O deformations in primary alcohols, and C=O stretching vibrations \\
856 & C-H vibrations in the positions of 2, 5, and 6 out of the plane of guaiacyl units \\
\hline
\end{tabular}

LHW process. It could be seen from Figure 2 that, after LHW pretreatment, the peaks of lignin at the bands of 1082, 1151, and $1367 \mathrm{~cm}^{-1}$ which were marked with the arrows appeared. The bands at 1082, 1151, and $1367 \mathrm{~cm}^{-1}$ are assigned to C-O deformation in the secondary alcohols and aliphatic ethers, $\mathrm{C}-\mathrm{O}$ stretching vibration in the tertiary alcohols, and $\mathrm{C}-\mathrm{H}$ stretching vibration in the aliphatic methyl and phenol $\mathrm{OH}$, respectively. The assignments of other characteristic peaks were summarized in Table 2. According to the enhanced absorbance of LHW-treated lignin, it could be inferred that some connections of chemical bonds in lignin were broken down, and some new free chemical groups were generated in the process of LHW pretreatment.

3.3. The Effect of Lignin on the Enzyme Activity and Adsorption. The main inhibition of lignin on enzymatic hydrolysis was thought to be the nonproductive adsorption of cellulase. Figure 3 showed the adsorption of cellulase to cellulose and treated lignin. The mixture of untreated lignin and citrate buffer presented brown color which interrupted the testing result. Therefore, the adsorption of cellulase to untreated lignin was not shown here. As time goes on, the adsorption of cellulase to treated lignin was at around 5\%, while the adsorption of cellulase to filter paper increased from $6.3 \%$ to $52.6 \%$. The adsorption of cellulase to the mixture of filter paper and treated lignin was nearly equal to the summation of individual adsorption from filter paper and treated lignin. It meant that the adsorption of cellulase was mainly attributed to the cellulose, which was corresponding to the previous research [23]. Zheng et al. [23] also found that the lignin imposed little impact on the apparent enzyme activity. The same phenomenon was observed in this study and presented in Figure 4. The enzyme activities with and without addition of lignin were measured. The relative enzyme activities were calculated as the ratio of enzyme activities with lignin to that

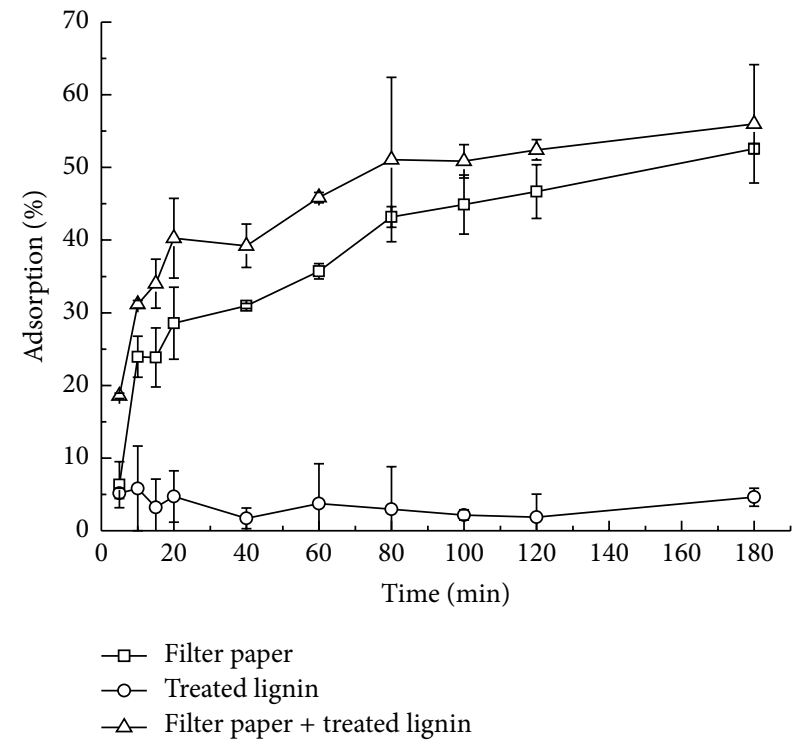

FIgURE 3: Adsorption of cellulase to LHW-treated lignin, filter paper, and their mixture.

without lignin. After adding untreated and treated lignin, the relative enzyme activities retained more than $90 \%$. The treated lignin hardly put impact on the CMCase activity. The little impact on the enzyme activities might be caused by the little adsorption of cellulase to lignin.

3.4. Enzymatic Hydrolysis. The effect of untreated and treated lignin on the enzymatic hydrolysis of cellulose was carried out in the $5 \mathrm{~mL}$ Eppendorf tubes which were sealed with parafilms to avoid the water evaporation. The mass ratio of lignin to cellulose was from $30 \%$ to $50 \%$ which was in 


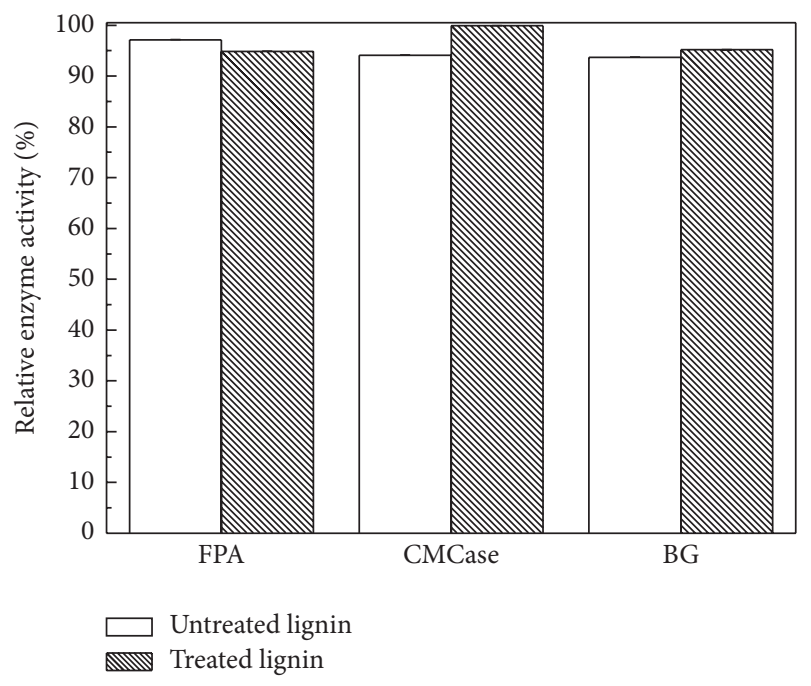

FIGURE 4: The effect of LHW-untreated and LHW-treated lignin on enzyme activities.

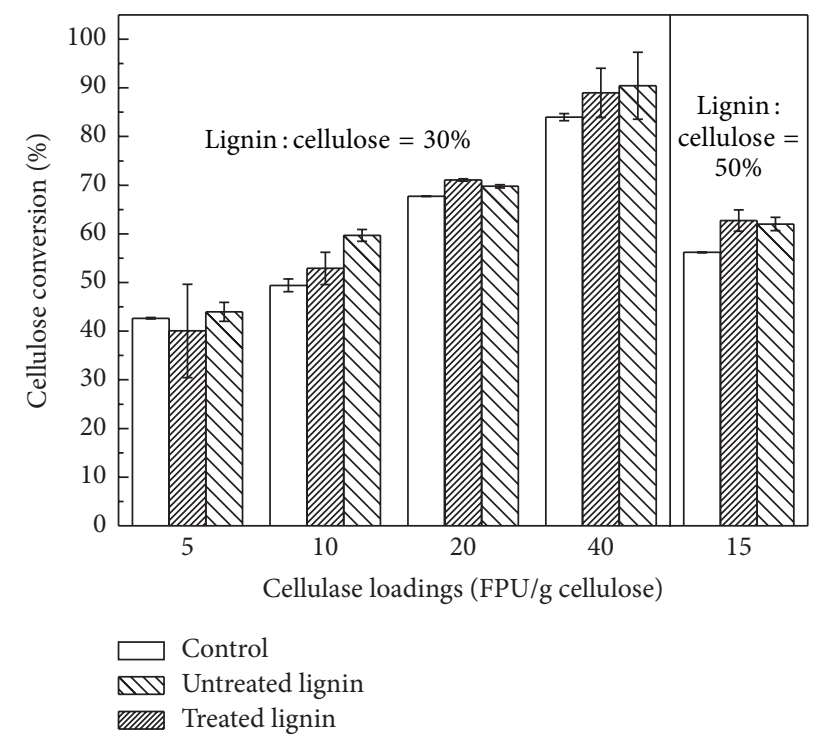

FIGURE 5: Enzymatic hydrolysis of filter paper in the presence of $\mathrm{LHW}$-untreated and LHW-treated lignin at $50^{\circ} \mathrm{C}$ for $72 \mathrm{~h}$.

analogy to the contents of lignin and cellulose in the LHWtreated biomass [18]. The ratio of solid to liquid was 5\% to relieve the negative effect of viscosity on the enzymatic hydrolysis. The effects of lignin and cellulase loadings on the enzymatic hydrolysis were explored, and the 72-hour enzymatic hydrolyzed results were shown in Figure 5.

Both untreated and treated lignin could improve the enzymatic hydrolysis of cellulose at the lignin loadings of $30 \%$ and $50 \%$ and cellulase loadings of $5,10,20$, and $40 \mathrm{FPU} / \mathrm{g}$ cellulose. These were contradictory with the previous researches which reported that lignin could inhibit the enzymatic hydrolysis of cellulose [24, 25]. Recently, several researches had reported that lignosulfonate could reduce the nonproductive adsorption of cellulase to lignin through the electrostatic repulsion or acting as the surfactant to enhance the enzymatic hydrolysis of lignocellulose [26-28]. Considering the isolation procedure of alkali lignin, the sulfur content of the alkali lignin used in this study was detected. It showed that the untreated and treated lignin had $1.83 \%$ and $1.23 \%$ sulfur content, respectively, which were lower than the least sulfur content of the lignosulfonate (5.27\%) used in Zhou's research [26]. The improvement of lignin on the enzymatic hydrolysis of cellulose might originate from the small part of lignosulfonate existing in the lignin. Although the treated lignin adsorbed a little cellulase and thus slightly reduced the enzyme activities (Figures 3 and 4), the enzymatic hydrolysis of cellulose was improved (Figure 5). This meant that the negative effect of LHW-treated lignin on the enzymatic hydrolysis could be neglected.

From Figure 5, it also could be seen that the cellulose conversion was increased with the cellulase loading increasing. Whatman number 1 filter paper was used as the pure cellulose to assay the enzyme activity of cellulase in Ghose's method [14]. When the cellulase loading achieved $40 \mathrm{FPU} / \mathrm{g}$ cellulose, the conversion of filter paper (the control in Figure 5) did not reach $100 \%$ but was just close to $85 \%$. It suggested that the lignin was not the main factor influencing the enzymatic hydrolysis. Although several researches had reported that the removal of lignin could enhance the enzymatic hydrolysis of lignocellulose [29-31], the methods used to remove lignin in their research could induce the structural changes of the lignocellulose. It would be not accurate to only discuss the effect of lignin removal on the enzymatic hydrolysis of lignocellulose. The crystallinity, particle size, nature of the residual lignin and substrate loading, and cellulose accessibility were reported to affect the enzymatic hydrolysis of cellulose [32-36]. The method to extract lignin from lignocellulose could more or less change the native structural characteristics of lignin. The investigation on the impact of lignin extractive on the enzymatic hydrolysis of cellulose may never reflect the real influence mechanism of lignin in the lignocellulose, but it can push the way to discover the truth. A method of reconstructing individual lignin, cellulose, and hemicellulose into a complex should be developed to simulate the lignocellulose. Through the reconstruction, the influence mechanism of lignocellulosic components and structure on enzymatic hydrolysis should be finally disclosed.

\section{Conclusion}

The research on the untreated and treated alkali lignin suggested that the chemical and structural characteristics of lignin were changed in the LHW process. The residual lignin in the LHW-treated lignocellulose which had similar structural and chemical features with the LHW-treated alkali lignin might put its impact on enzymatic hydrolysis of cellulose not via the nonproductive adsorption of cellulase.

\section{Competing Interests}

The authors declare that there is no conflict of interests regarding the publication of this paper. 


\section{Acknowledgments}

This study was financially supported by the National Basic Research Program of China (973 Program, 2012CB215300), the National Natural Science Foundation of China (21476233, 51176196, 21206163, and 21506216), and the President Innovation Foundation of Guangzhou Institute of Energy Conversion $(\mathrm{y} 207 \mathrm{rl})$.

\section{References}

[1] A. R. C. Morais, A. M. Da Costa Lopes, and R. Bogel-Łukasik, "Carbon dioxide in biomass processing: contributions to the green biorefinery concept," Chemical Reviews, vol. 115, no. 1, pp. 3-27, 2015.

[2] L. Paulova, P. Patakova, B. Branska, M. Rychtera, and K. Melzoch, "Lignocellulosic ethanol: technology design and its impact on process efficiency," Biotechnology Advances, vol. 33, no. 6, pp. 1091-1107, 2015.

[3] M. Shafiei, K. Karimi, H. Zilouei, and M. J. Taherzadeh, "Enhanced ethanol and biogas production from pinewood by NMMO pretreatment and detailed biomass analysis," BioMed Research International, vol. 2014, Article ID 469378, 10 pages, 2014.

[4] W. Wang, X. Zhuang, Z. Yuan, Q. Yu, and W. Qi, "Investigation of the pellets produced from sugarcane bagasse during liquid hot water pretreatment and their impact on the enzymatic hydrolysis," Bioresource Technology, vol. 190, pp. 7-12, 2015.

[5] J. K. Ko, E. Ximenes, Y. Kim, and M. R. Ladisch, "Adsorption of enzyme onto lignins of liquid hot water pretreated hardwoods," Biotechnology and Bioengineering, vol. 112, no. 3, pp. 447-456, 2015.

[6] Y. Kim, T. Kreke, J. K. Ko, and M. R. Ladisch, "Hydrolysisdetermining substrate characteristics in liquid hot water pretreated hardwood," Biotechnology and Bioengineering, vol. 112, no. 4, pp. 677-687, 2015.

[7] J. K. Ko, Y. Kim, E. Ximenes, and M. R. Ladisch, "Effect of liquid hot water pretreatment severity on properties of hardwood lignin and enzymatic hydrolysis of cellulose," Biotechnology and Bioengineering, vol. 112, no. 2, pp. 252-262, 2015.

[8] S. Nakagame, R. P. Chandra, J. F. Kadla, and J. N. Saddler, “The isolation, characterization and effect of lignin isolated from steam pretreated Douglas-fir on the enzymatic hydrolysis of cellulose," Bioresource Technology, vol. 102, no. 6, pp. 4507-4517, 2011.

[9] A. Fujimoto, Y. Matsumoto, H.-M. Chang, and G. Meshitsuka, "Quantitative evaluation of milling effects on lignin structure during the isolation process of milled wood lignin," Journal of Wood Science, vol. 51, no. 1, pp. 89-91, 2005.

[10] T. Ikeda, K. Holtman, J. F. Kadla, H.-M. Chang, and H. Jameel, "Studies on the effect of ball milling on lignin structure using a modified DFRC method," The Journal of Agricultural and Food Chemistry, vol. 50, no. 1, pp. 129-135, 2002.

[11] H. M. Chang, E. B. Cowling, W. Brown, E. Adler, and G. Miksche, "Comparative studies on cellulolytic enzyme lignin and milled wood lignin of sweetgum and spruce," Holzforschung, vol. 29, pp. 153-159, 1975.

[12] D. She, F. Xu, Z. Geng, R. Sun, G. L. Jones, and M. S. Baird, "Physicochemical characterization of extracted lignin from sweet sorghum stem," Industrial Crops and Products, vol. 32, no. 1, pp. 21-28, 2010.
[13] R. Sun, J. M. Lawther, and W. B. Banks, "Effects of extraction time and different alkalis on the composition of alkali-soluble wheat straw lignins," The Journal of Agricultural and Food Chemistry, vol. 44, no. 12, pp. 3965-3970, 1996.

[14] Q. Yu, X. Zhuang, Q. Wang, W. Qi, X. Tan, and Z. Yuan, "Hydrolysis of sweet sorghum bagasse and eucalyptus wood chips with liquid hot water," Bioresource Technology, vol. 116, pp. 220-225, 2012.

[15] K. Ghose T, "Measurement of cellulose activities," Pure \& Applied Chemistry, vol. 59, pp. 257-268, 1987.

[16] W. Wang, X. Zhuang, Z. Yuan et al., "Highly efficient conversion of sugarcane bagasse pretreated with liquid hot water into ethanol at high solid loading," International Journal of Green Energy, vol. 13, no. 3, pp. 298-304, 2016.

[17] A. Sluiter, B. Hames, R. Ruiz et al., "Determination of structural carbohydrates and lignin in biomass," Tech. Rep. NREL/TP-51042618, 2008.

[18] W. Wang, X. Zhuang, Z. Yuan et al., "Effect of structural changes on enzymatic hydrolysis of eucalyptus, sweet sorghum bagasse, and sugarcane bagasse after liquid hot water pretreatment," Bioresources, vol. 7, no. 2, pp. 2469-2482, 2012.

[19] B. S. Donohoe, S. R. Decker, M. P. Tucker, M. E. Himmel, and T. B. Vinzant, "Visualizing lignin coalescence and migration through maize cell walls following thermochemical pretreatment," Biotechnology and Bioengineering, vol. 101, no. 5, pp. 913925, 2008.

[20] X. Luo and J. Y. Zhu, "Effects of drying-induced fiber hornification on enzymatic saccharification of lignocelluloses," Enzyme and Microbial Technology, vol. 48, no. 1, pp. 92-99, 2011.

[21] M. Zeng, E. Ximenes, M. R. Ladisch et al., “Tissue-specific biomass recalcitrance in corn stover pretreated with liquid hotwater: SEM imaging (part 2)," Biotechnology and Bioengineering, vol. 109, no. 2, pp. 398-404, 2012.

[22] M. Poletto, A. J. Zattera, and R. M. C. Santana, "Structural differences between wood species: evidence from chemical composition, FTIR spectroscopy, and thermogravimetric analysis," Journal of Applied Polymer Science, vol. 126, no. 1, pp. E336-E343, 2012.

[23] Y. Zheng, S. Zhang, S. Miao, Z. Su, and P. Wang, “Temperature sensitivity of cellulase adsorption on lignin and its impact on enzymatic hydrolysis of lignocellulosic biomass," Journal of Biotechnology, vol. 166, no. 3, pp. 135-143, 2013.

[24] A. Várnai, M. Siika-aho, and L. Viikari, "Restriction of the enzymatic hydrolysis of steam-pretreated spruce by lignin and hemicellulose," Enzyme and Microbial Technology, vol. 46, no. 3-4, pp. 185-193, 2010.

[25] J. L. Rahikainen, R. Martin-Sampedro, H. Heikkinen et al., "Inhibitory effect of lignin during cellulose bioconversion: the effect of lignin chemistry on non-productive enzyme adsorption," Bioresource Technology, vol. 133, pp. 270-278, 2013.

[26] H. Zhou, H. Lou, D. Yang, J. Y. Zhu, and X. Qiu, "Lignosulfonate to enhance enzymatic saccharification of lignocelluloses: role of molecular weight and substrate lignin," Industrial $\mho$ Engineering Chemistry Research, vol. 52, no. 25, pp. 8464-8470, 2013.

[27] Z. Wang, J. Y. Zhu, Y. Fu et al., "Lignosulfonate-mediated cellulase adsorption: Enhanced enzymatic saccharification of lignocellulose through weakening nonproductive binding to lignin," Biotechnology for Biofuels, vol. 6, article 156, 2013.

[28] H. Lou, M. Wang, H. Lai et al., "Reducing non-productive adsorption of cellulase and enhancing enzymatic hydrolysis of lignocelluloses by noncovalent modification of lignin with 
lignosulfonate," Bioresource Technology, vol. 146, pp. 478-484, 2013.

[29] S. I. Mussatto, M. Fernandes, A. M. F. Milagres, and I. C. Roberto, "Effect of hemicellulose and lignin on enzymatic hydrolysis of cellulose from brewer's spent grain," Enzyme and Microbial Technology, vol. 43, no. 2, pp. 124-129, 2008.

[30] G. J. M. Rocha, V. F. N. Silva, C. Martín, A. R. Gonçalves, V. M. Nascimento, and A. M. Souto-Maior, "Effect of xylan and lignin removal by hydrothermal pretreatment on enzymatic conversion of sugarcane bagasse cellulose for second generation ethanol production," Sugar Tech, vol. 15, no. 4, pp. 390-398, 2013.

[31] S. Lv, Q. Yu, X. Zhuang et al., "The influence of hemicellulose and lignin removal on the enzymatic digestibility from sugarcane bagasse," Bioenergy Research, vol. 6, no. 4, pp. 1128-1134, 2013.

[32] L. Rosgaard, P. Andric, K. Dam-Johansen, S. Pedersen, and A. S. Meyer, "Effects of substrate loading on enzymatic hydrolysis and viscosity of pretreated barley straw," Applied Biochemistry and Biotechnology, vol. 143, no. 1, pp. 27-40, 2007.

[33] M. Yoshida, Y. Liu, S. Uchida et al., "Effects of cellulose crystallinity, hemicellulose, and lignin on the enzymatic hydrolysis of Miscanthus sinensis to monosaccharides," Bioscience, Biotechnology and Biochemistry, vol. 72, no. 3, pp. 805-810, 2008.

[34] S. Nakagame, R. P. Chandra, and J. N. Saddler, "The effect of isolated lignins, obtained from a range of pretreated lignocellulosic substrates, on enzymatic hydrolysis," Biotechnology and Bioengineering, vol. 105, no. 5, pp. 871-879, 2010.

[35] A.-I. Yeh, Y.-C. Huang, and S. H. Chen, "Effect of particle size on the rate of enzymatic hydrolysis of cellulose," Carbohydrate Polymers, vol. 79, no. 1, pp. 192-199, 2010.

[36] J. A. Rollin, Z. Zhu, N. Sathitsuksanoh, and Y.-H. P. Zhang, "Increasing cellulose accessibility is more important than removing lignin: a comparison of cellulose solvent-based lignocellulose fractionation and soaking in aqueous ammonia," Biotechnology and Bioengineering, vol. 108, no. 1, pp. 22-30, 2011. 

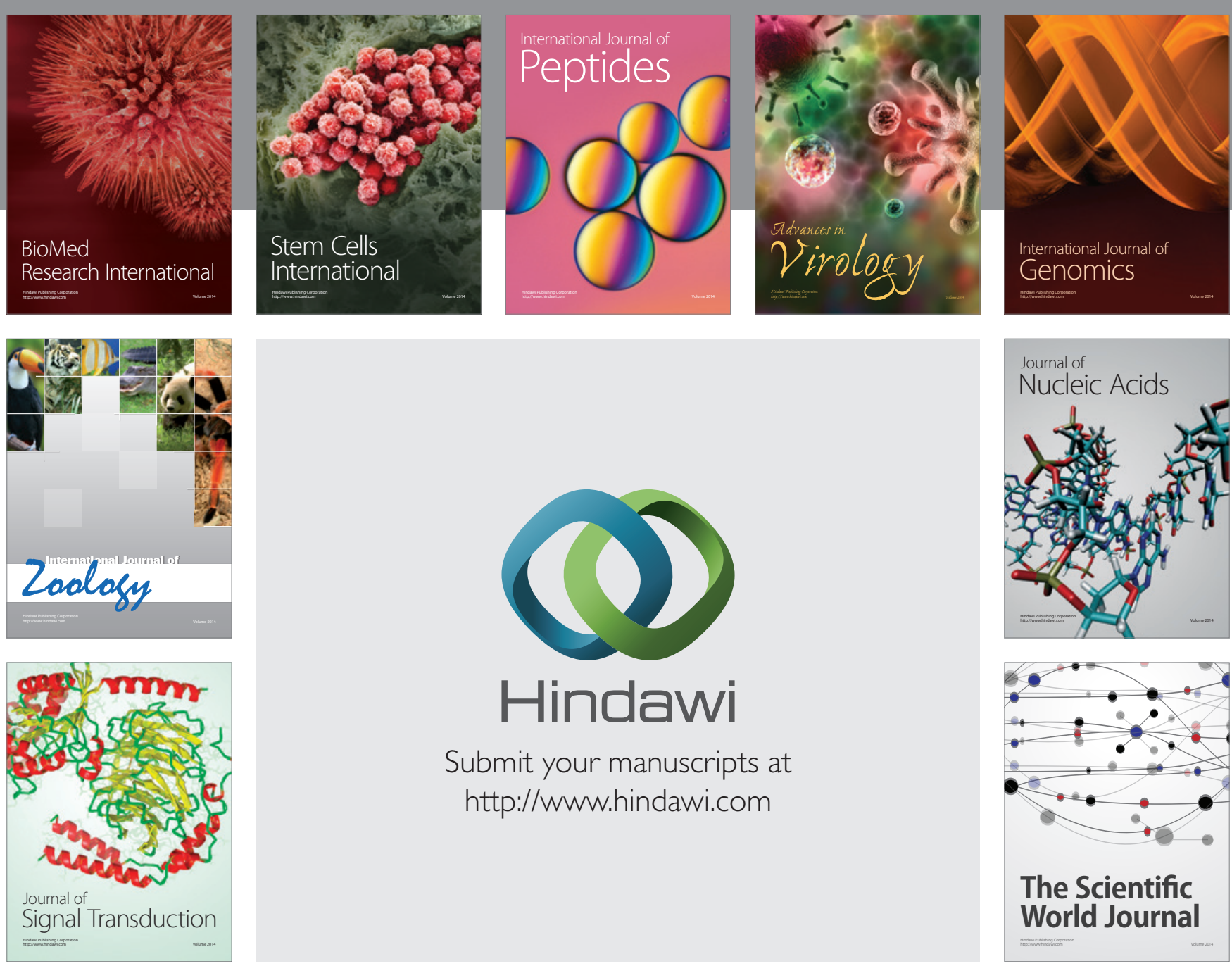

Submit your manuscripts at

http://www.hindawi.com
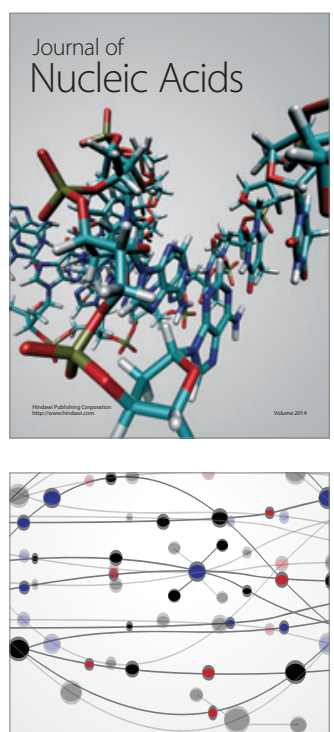

The Scientific World Journal
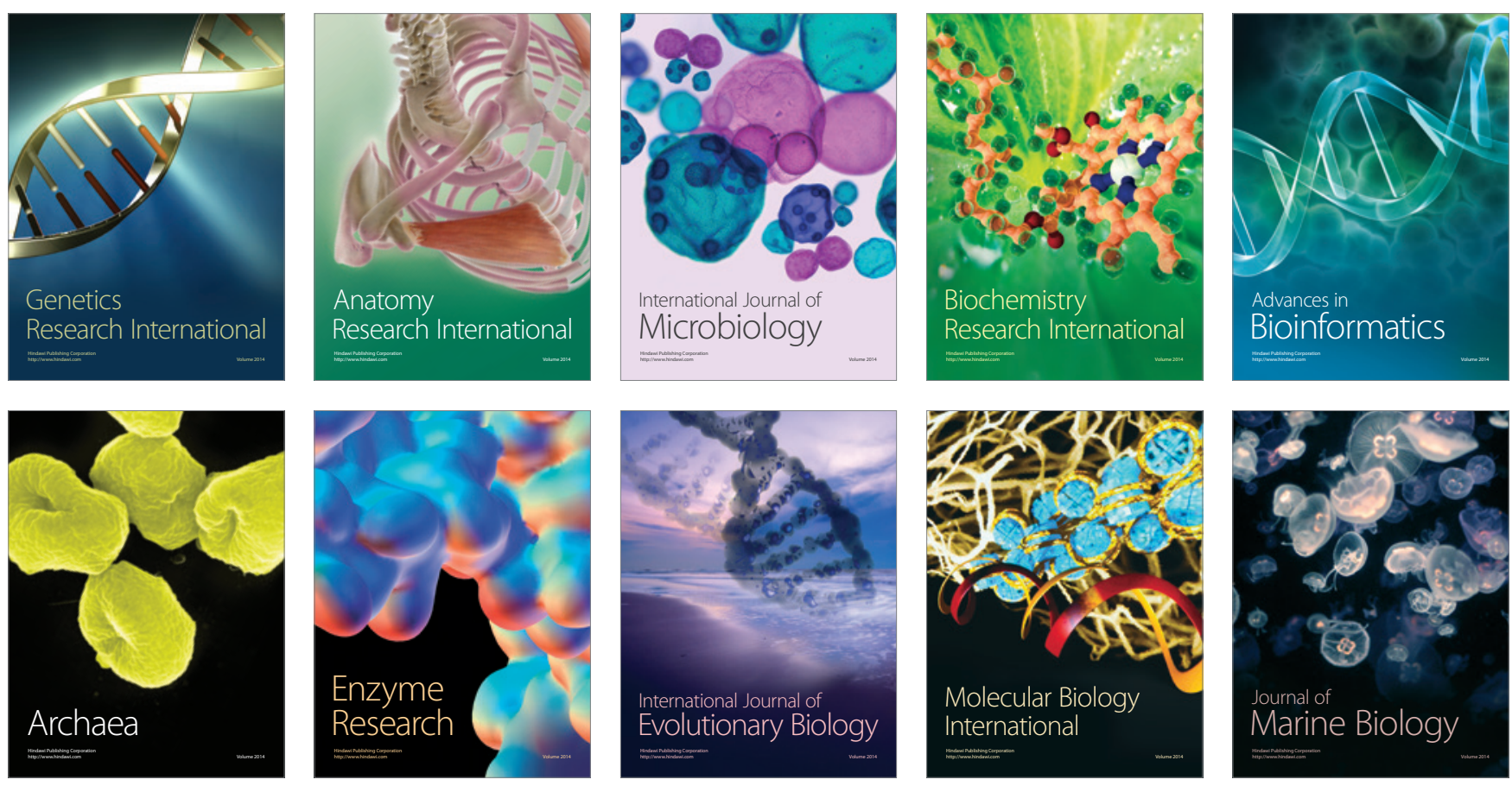